\title{
Agora a cadeia pesou: aportes sobre os movimentos da Covid-19 no sistema prisional brasileiro
}

\author{
Now jail has become a heavy burden: contributions on \\ COVID-19 movements in the Brazilian prison system
}

\section{Ahora la cárcel se ha vuelto pesada: contribuciones sobre los movimientos del COVID-19 en el sistema penitenciario brasileño}

\author{
iD Simone da Silva Ribeiro Gomes \\ Universidade Federal de Pelotas, Pelotas, Rio Grande do Sul, Brasil \\ simone.gomes@ufpel.edu.br \\ (iD) Eduardo Pinheiro Urrutia \\ Universidade Federal de Pelotas, Pelotas, Rio Grande do Sul, Brasil \\ dudaurrutia@yahoo.com.br
}

Resumo: O artigo parte de um trabalho qualitativo, de inspiração etnográfica, realizado em um presídio em Rio Grande, no Rio Grande do Sul, para explorar algumas dinâmicas da justiça criminal e do sistema penitenciário ocasionadas pela pandemia de Covid-19 em 2020. Nossa hipótese é que as dinâmicas recentes observadas por detrás das grades são reflexos de movimentos à frente delas, notadamente das decisões do Ministério da Justiça, mas também das facções prisionais, relevantes na análise. As conclusões dizem respeito às vivências de pessoas presas em um período de aguçamento de suas condições de visita e as moedas de troca estabelecidas: a (iminência de) rebelião de um lado e a ausência de visitas, de outro. Distintos movimentos são analisados a partir das dinâmicas do Executivo e Judiciário, na esfera estatal, e da resposta dos presídios, no escopo do disciplinamento interno das penitenciárias.

Palavras-chave: Sistema penitenciário. Covid-19. Epidemia. Visitas. Rebelião. 
Abstract: The article derives from a qualitative, ethnographical work, carried out in a prison in Rio Grande, Rio Grande do Sul, Brazil, to explore some of the criminal justice and prison system dynamics induced by the COVID-19 pandemic in 2020. Our assumption is that recent dynamics observed from behind the bars reflect movements free from the bars, notably decisions by the Ministry of Justice, but also in-prison criminal organizations, relevant to analysis. The conclusions refer to experiences of imprisoned people in a period of poorer visiting conditions and the exchange currencies set up: on the one hand, (imminence of) rebellion and, on the other, absence of visits. Various movements are analyzed by means of the Executive and Judiciary power dynamics, at the state level, and the response of prisons, within the scope of in-prison discipline.

Keywords: Prison system. COVID-19. Epidemic. Visits. Rebellion.

Resumen: El artículo parte de un trabajo cualitativo, de inspiración etnográfica, realizado en una prisión de Rio Grande, Rio Grande do Sul, Brasil, para explorar algunas dinámicas de la justicia criminal y del sistema penitenciario provocadas por la pandemia de COVID-19 en 2020. Nuestra hipótesis es que las dinámicas recientes observadas tras las rejas son un reflejo de los movimientos por delante de estas, en particular las decisiones del Ministerio de Justicia, pero también las facciones carcelarias, relevantes en el análisis. Las conclusiones se refieren a las vivencias de personas arrestadas en un período de peores condiciones de visita y las monedas de cambio establecidas: la (inminencia de) rebelión, por un lado, y la ausencia de visitas, por otro. Se analizan diferentes movimientos a partir de las dinámicas de los poderes Ejecutivo y Judicial, a nivel del estado, y de la respuesta de las prisiones, en el ámbito de la disciplina interna de las penitenciarías.

Palabras clave: Sistema penitenciario. COVID-19. Epidemia. Visitas. Rebelión.

Data de submissão: 10/10/2020

Data de aprovação: 13/02/2021 


\section{Introdução}

O sistema prisional brasileiro, com cerca de 748 mil $^{1}$ detentos em cumprimento de pena em diferentes tipos de regimes, atualmente o terceiro mais populoso do mundo, reagiu de maneira emblemática à entrada do vírus Sars CoV-2, em 2020, em suas unidades. É notório que as prisões em todo seu território são historicamente definidas como espaços de aglomeração, escassa ventilação e atendimento médico precário, o que acaba por configurar um polo ideal para a disseminação de doenças infecciosas. Contudo, a recepção do problema epidemiológico e sanitário brasileiro nas unidades prisionais apresentou especificidades a um problema comum em todo o mundo, a saber, a persistência do encarceramento de sujeitos e como estes espaços são ambientes exemplares para a propagação de doenças.

O objetivo do artigo é investigar os indícios de mudanças no paradigma de encarceramento no Brasil a partir do desencadeamento da epidemia de Covid-19 e seu rápido espalhamento no país. As medidas tomadas nos primeiros meses pelo Conselho Nacional de Justiça (CNJ) são o principal objeto de análise neste trabalho, tal como as dinâmicas subsequentes relativas à doença. Elas incluem movimentos de negociação em polos opostos: do lado estatal, a suspensão das visitas e os efeitos nas vidas das pessoas presas; em outro polo, o aguçamento de suas condições de vida em confinamento e a ameaça de rebelião, em alguns contextos.

Em relação à metodologia, o artigo fez uso de uma abordagem qualitativa com uma observação participante e uma pesquisa de inspiração etnográfica em uma unidade prisional na cidade de Rio Grande, no Rio Grande do Sul. Foi iniciada em março, mas prosseguiu durante o período da pandemia de Covid-19. A entrada e observação em uma unidade prisional foi facilitada por conta do vínculo empregatício de um dos autores. Embora, seguramente, a proximidade com as pessoas presas não garanta uma posição

1 Segundo dados do INFOPEN. Disponível em: http://depen.gov.br/DEPEN/depen/sisdepen/infopen. Acesso em: 5 de agosto de 2020. 
Agora a cadeia pesou: aportes sobre os movimentos da Covid-19 no sistema prisional brasileiro Simone da Silva Ribeiro Gomes • Eduardo Pinheiro Urrutia

de simetria, o convívio próximo revelou, em certa medida, alguns anseios dos apenados com a pandemia.

Nessesentido, tanto a abordagem proposta pela paraetnografia (ISLAM, 2014) quanto as reflexões etnográficas de Wacquant(2002a; 2002b) foram relevantes para a pesquisa. A primeira enfatiza o caráter colaborativo dos experimentos dos sujeitos envolvidos no campo. Eles, para o método paraetnográfico, são colaboradores e não somente informantes, o que auxiliou os autores, dada a frequência das interações com as pessoas presas. A importância deste método reside na possibilidade de explorar a familiaridade dos sujeitos envolvidos na pesquisa, e seus limites metodológicos versam, sobretudo, sobre a delimitação de fronteiras da atividade profissional prévia dos pesquisadores e sua inserção no campo. A exemplo de Wacquant (2002a; 2002b), que igualmente aborda a relação de proximidade entre os boxeadores e o pesquisador (também ele, um lutador de boxe amador) em seu trabalho, de maneira que reflete sobre sua atividade profissional no âmbito desta dupla inserção.

O artigo se inicia com uma discussão sobre as convergências no debate da pandemia no sistema prisional no mundo e no Brasil, em seu debate sobre as condições de insalubridade e aglomeração suscitadas pelo crescente aprisionamento de seres humanos no século XXI. Em um segundo momento, discutimos a instabilidade e negociações em que foram recebidas a pandemia no sistema penitenciário no Brasil, a partir das decisões do Conselho Nacional de Justiça (CNJ) e, finalmente, as considerações finais versam sobre os movimentos observados no contexto prisional e os impactos das decisões dos principais atores no campo.

\section{O global e o nacional nas dinâmicas das unidades prisionais e a Covid-19}

Tendo em vista que o aprisionamento como punição, da forma como conhecemos, é uma realidade datada historicamente, 
Agora a cadeia pesou: aportes sobre os movimentos da Covid-19 no sistema prisional brasileiro Simone da Silva Ribeiro Gomes • Eduardo Pinheiro Urrutia

que remonta ao século XVIII na Europa e ao XIX nos EUA (DAVIS, 2019; GILMORE, 2007), é importante levar em consideração como o debate sobre a Covid-19 foi inflexionado atualmente no sistema prisional. As situações foram recebidas com preocupação em todo o mundo, quando, no começo de 2020, a pandemia iniciou seu rápido alastramento, o que pressupunha uma velocidade ainda maior de infecção nas unidades prisionais. No Brasil, o ambiente prisional nos vem à mente quando se pensa em aglomerações, tal como estádios de futebol, festas e concertos de música, por exemplo, logo, a infecção seria espalhada rapidamente.

Nos EUA, com a irrupção da pandemia de Covid-19, o primeiro movimento do prefeito Bill de Blasio, na cidade de Nova York, foi um aceno favorável à soltura de alguns presos ${ }^{2}$ após constatada a necessidade de um lockdown. O mesmo ocorreu em outros grandes centros urbanos como Pennsylvania, Los Angeles e Cleveland, entre outras cidades no país. Ato contínuo, coletivos organizados nesses contextos, como o Bay Area Transformative Justice Collective, na California, Safe OUTside the System Collective, em Nova lorque e o $P a^{\prime}$ late Restorative Justice, em Massachusetts, foram responsáveis por liderar algumas das discussões pelo desencarceramento gradual e sistemático nesse cenário (HELEPOLOLEl, 2020). No total, 122 presídios federais e a maioria dos 1700 estabelecimentos estaduais estadunidenses suspenderam a entrada de visitantes, voluntários e advogados, inclusive as visitas que anteriormente faziam uso das divisórias de vidro.

Com efeito, nos EUA, a recorrente discussão sobre abolição das prisões e racismo seletivo do Estado $^{3}$ pode ser embasada em uma ampla literatura que relaciona o racismo estatal e a seletividade penal (SKARBEK, 2011; DAVIS, 2019; GILMORE, 2007; PASSETTI, 1997). Ademais, a Covid-19 trouxe à tona os perigos adicionais do encarceramento de jovens por crimes menores, e como esse ciclo de prisão, e subsequente soltura, aumenta os

\footnotetext{
2 Disponível em: https://nypost.com/2020/03/22/coronavirus-in-ny-city-to-release-23-more-inmates-amid-jail-system-outbreak/. Acesso em: 8 ago. 2020.

3 Disponível em: https://jacobinmag.com/2020/03/prison-jail-coronavirus-release-abolition-incarceration? Acesso em: 8 ago. 2020.
} 
Agora a cadeia pesou: aportes sobre os movimentos da Covid-19 no sistema prisional brasileiro Simone da Silva Ribeiro Gomes • Eduardo Pinheiro Urrutia

riscos das comunidades pobres com maioria de negros em sua população ${ }^{4}$. À discussão sobre a possibilidade de libertação dos presos seguiu-se um intenso debate sobre o abolicionismo penal, afinal, é cada vez mais complexo seguir com o confinamento de sujeitos nas condições contemporâneas, em todo o mundo.

Essa discussão já acontece mais ao sul no continente, ainda que de forma inédita com essa intensidade (ALVES e GUSIS, 2019). A América Latina possui um alto índice de detenção provisória, maior do que no restante do mundo (PERICE, 2020), o que influencia diretamente na superlotação de suas unidades. Ademais, os discursos mormente conectados às perspectivas que defendem um "populismo penal" (PERICE, 2020; SOZZO, 2015) são frequentes na região, com a demanda de um endurecimento de penas e diminuição da idade para encarceramento ${ }^{5}$, mesmo que 0 procedimento legal seja burlado nesses processos.

No Brasil, especificamente, cabe apontar como, em março de 2020, no início do alarme da sociedade frente à pandemia, a resposta passou - ainda que rapidamente - por soluções discutidas anteriormente no amplo guarda-chuva do abolicionismo penal (PASSETTI, 1997; 2005; BATISTA, 2004), dadas as condições precárias de aprisionamento. A recomendação 62/2020 do CNJ, editada em 17 de março de $2020^{6}$, que versa sobre a adoção de medidas preventivas à propagação da infecção pela Covid-19 no âmbito dos sistemas de justiça penal e socioeducativo, apontou para soluções de soltura de presos de menor risco. A mesma preconizava a substituição das penas de prisão de pessoas em grupos de risco e no final de suas penas por outras medidas, como a prisão domiciliar. A decisão, foi prorrogada por mais noventa dias e alterada para a inclusão de um novo dispositivo sobre audiências de custódia, que foram suspensas em diversos tribunais em razão da pandemia.

\footnotetext{
4 Discussão com base nos trabalhos de Eric Reinhart. Disponível em: https://www.nytimes.com/2020/07/02/opinion/coronavirus-jail.html?action=click\&module=Opinion\&pgtype=Homepage. Acesso em: 10 ago. 2020.

5 Algumas tentativas recentes de pautar a diminuição da maioridade penal foram levadas à Câmara dos Deputados, dentre as quais destacamos o envio da PEC de diminuição da maioridade de 18 para 16 anos em 2015, que foi, em último momento, derrotada. Contudo, esta discussão é recorrente, no Brasil e na América Latina, de forma geral.

6 Disponível em: https://atos.cnj.jus.br/atos/detalhar/3246. Acesso em: 19 ago. 2020.
} 
Agora a cadeia pesou: aportes sobre os movimentos da Covid-19 no sistema prisional brasileiro Simone da Silva Ribeiro Gomes • Eduardo Pinheiro Urrutia

Importa afirmar que o CNJ cumpre o papel de editar normativas, que serão seguidas pelas Varas de Execução locais em suas portarias, com regras para soltar determinados detentos, quer seja por configurarem em um grupo de risco, ou para o uso da tornozeleira eletrônica. Nesse sentido, em um primeiro momento, o número de presos soltos provisoriamente foi elevado, tendo em vista o histórico dessas decisões na instituição criada em 2004, em funcionamento desde 2005.

A decisão foi considerada acertada por parte significativa da sociedade civil. Um manifesto assinado por cerca de 70 entidades e organizações apoiou as medidas de desencarceramento propostas pela decisão7. Adicionalmente, a Plataforma Desencarcera!, iniciativa do Instituto DH: Promoção, Pesquisa e Intervenção em Direitos Humanos e Cidadania em parceria com o Laboratório de Estudos sobre Trabalho, Cárcere e Direitos Humanos - UFMG e com o Grupo de Amigo/as e Familiares de Pessoas em Privação de Liberdade - MG, lançou o Manifesto sem Prisões, no início de 2020.

Isso posto, o Brasil tem - na ameaça - na ocorrência de rebeliões um interlocutor oculto, uma ameaça recorrente no sistema prisional, dada a organização em facções prisionais (SALLA, 2006). Dessa forma, uma determinação da Justiça de São Paulo para a suspensão das saidinhas da Páscoa para evitar o contágio do coronavírus quando do regresso desses presos ao sistema foi o primeiro estopim para o descontentamento dos detentos e o aumento da instabilidade no sistema prisional ${ }^{8}$. Afinal, a rebelião nos presídios sempre está à espreita.

Em um movimento que indicava um recuo, em julho foi emitida uma nova resolução que revogava a realização de videoconferência das audiências de custódia. Assim, mesmo durante a pandemia, as audiências teriam que ser realizadas presencialmente, em obediência ao Código de Processo Penal e a resolução n. 213/2015,

7 Disponível em: http://pbpd.org.br/manifesto-em-apoio-a-recomendacao-62-do-cnj-e-ao-desencarceramento/. Acesso em: 7 ago. 2020 .

8 Disponível em: https://piaui.folha.uol.com.br/o-pcc-e-o-virus-das-rebelioes/. Acesso em: 7 ago. 2020. 
Agora a cadeia pesou: aportes sobre os movimentos da Covid-19 no sistema prisional brasileiro Simone da Silva Ribeiro Gomes • Eduardo Pinheiro Urrutia

com a justificativa de que os vídeos dificultariam a identificação de prática de tortura. Tais acontecimentos ocorreram em meio ao imbróglio da gestão do Ministério da Justiça e Segurança Pública (MJSP), que culminaram, no final de abril, com a saída do então ministro, Sérgio Moro, que em um primeiro momento foi reticente a editar normas de suspensão de visitas. Em um momento anterior, o ministro se posicionou contrário à soltura de apenados não condenados por violência ou grave ameaça e emitiu portarias definindo medidas como o isolamento de detentos com a confirmação ou suspeita de Covid-19; o uso de cortinas e marcações no chão das unidades para delimitar distância mínima entre os internos e a suspensão ou redução de reuniões religiosas ou de grupos de assistência (CAMPELLO, 2020).

Nesse sentido, o poder executivo mostrou-se contrário à soltura temporária, mas o judiciário a favor, em um movimento importante de ser ressaltado, dado que no âmbito da Segurança Pública, no Brasil, há uma maior responsividade ao Poder Judiciário. Na ponta, é de responsabilidade do juiz de Vara de Execução local realizar a soltura, logo, as decisões do judiciário aparecem como mais consensuais.

No que tange à posição de soltura dos presos, a Pastoral Carcerária9 e o Instituto de Defesa do Direito de Defesa (IDDD) foram entidades que enfatizaram a fragilidade à qual estão sujeitas as pessoas presas em um cenário de pandemia, uma vez que essas populações já possuem imunidade baixa, dadas as condições de encarceramento. A existência de outra doença infectorespiratória, tuberculose (TB), aparece como prova disso (BONATO, VENTURA e CAETANO, 2020), com uma incidência 30 vezes maior nas unidades prisionais do que na sociedade em geral ${ }^{10}$. Segundo Machado et al. (2016), essa enfermidade é considerada uma das maiores responsáveis por mortes no sistema, especialmente por espalhar-

9 Disponível em: https://carceraria.org.br/combate-e-prevencao-a-tortura/carta-aberta-da-pastoral-carceraria-nacional-sobre-coronavirus-nas-prisoes. Acesso em: 7 ago. 2020.

10 Disponível em: https://oglobo.globo.com/sociedade/saude/incidencia-de-tuberculose-em-presos-30-vezes-maior-do-que-na-populacao-geral-22540362. Acesso em: 7 ago. 2020. 
Agora a cadeia pesou: aportes sobre os movimentos da Covid-19 no sistema prisional brasileiro Simone da Silva Ribeiro Gomes • Eduardo Pinheiro Urrutia

se em ambientes insalubres e sem políticas de controle da doença, como nos estabelecimentos prisionais.

Entretanto, a incursão etnográfica nos mostrou o quanto a recorrência histórica da TB no sistema ocasionou que a mesma fosse encarada com certa naturalidade, ao passo que a Covid-19 foi recebida como preocupante pelos diretores. Na cidade de Rio Grande, por exemplo, os responsáveis administrativos pelas unidades chamaram as pessoas presas para conversar, de forma a dividir suas preocupações com o avanço da doença, e assim justificar as medidas de forte impacto que seriam tomadas e tentar evitar desdobramentos, como motins, fugas e rebeliões.

Observamos então um embate no bojo do que Zelizer (2009) conceituou como dualismos perigosos, ou seja, a criação e manutenção de polos opostos, quando dicotomias são utilizadas em determinados contextos para adjetivar as posições dos sujeitos em um assunto específico. Valença e Freitas (2020), por exemplo, em sua análise de decisões judiciais sobre a soltura de presos, evidenciam uma disputa de posições entre aqueles que priorizaram o direito à vida, neste momento, frente àqueles que defendem, primeiramente, o valor da defesa social. São reflexos de uma polarização da sociedade no Brasil contemporâneo. No próximo item, discutiremos algumas repercussões nos movimentos dentro do sistema prisional brasileiro, a partir de um trabalho de inspiração etnográfica.

\section{Os desdobramentos da Covid-19 nas unidades prisionais no Brasil: o caso da PERG em Rio Grande}

As prisões brasileiras, com suas insalubridades construídas historicamente (MAIA, 2009), adquiriram, com a irrupção da pandemia de Covid-19, contornos distintivos. Os desafios recentes relativos ao encarceramento acelerado das últimas décadas e a organização dos presos em coletivos conhecidos como gangues (LOURENÇO, 2013) ou facções criminosas (PAIVA, 2019) são im- 
Agora a cadeia pesou: aportes sobre os movimentos da Covid-19 no sistema prisional brasileiro Simone da Silva Ribeiro Gomes • Eduardo Pinheiro Urrutia

portantes para o entendimento das dinâmicas deflagradas pela doença no sistema. Primeiramente, a normativa que determinava o impedimento de acesso às visitas aos detentos, emitida em março de 2020, comprometeu igualmente a possibilidade de uma pesquisa de campo nesse contexto.

Embora seja convergente ao desafio de outras áreas de pesquisa durante a pandemia, neste caso, o limitado acesso dos atores a outros meios de comunicação tornaram maiores as dificuldades em conhecer os anseios das pessoas presas, bem como entender quais mudanças decorrentes da Covid-19 elas vivenciaram. Conforme o Boletim Semanal de Registros de Contágios e Óbitos do CNJ, até 16 de setembro de 2020 o sistema prisional brasileiro registrou 34.961 casos confirmados e 192 óbitos entre pessoas presas e servidores penitenciários. ${ }^{11}$

No município de Rio Grande, no Rio Grande do Sul, há atualmente 848 pessoas presas no estabelecimento prisional: 563 no sistema fechado, 8 no semiaberto, 2 no aberto e 275 em regime provisório ${ }^{12}$. A Penitenciária Estadual de Rio Grande (PERG) é a responsável por abrigar tais detentos, e o aumento recente de pessoas presas se deu graças às modificações recentes que incluíram uma reforma no presídio do município vizinho, Pelotas. Isso ocasionou a transferência temporária de apenados de uma unidade à outra. A apresentação inicial desse presídio levou em conta informações sobre o campo da pesquisa, assim como da posição de imersão que possibilitou as observações.

A PERG é um estabelecimento prisional com capacidade para 488 detentos, mas cuja lotação atual está próxima ao dobro de sua capacidade. Além de superlotado, o estabelecimento é misto, logo, o único que tem vagas femininas na região sul do Rio Grande do Sul, de forma que todas as 80 apenadas do extremo sul do Brasil se encontram atualmente nesse local. Ademais, a unidade gerencia também cerca de 230 apenados do regime semiaberto em prisão domiciliar com tornozeleira e mais 340 do regime aberto em

11 CNJ - Boletim Semanal de Registros. Disponível em: https://www.cnj.jus.br/sistema-carcerario/covid-19/registros-de-contagios-obitos/. Acesso em: 08 jul. 2020.

12 Segundo dados do INFOPEN. Disponível em: http://depen.gov.br/DEPEN/depen/sisdepen/infopen. Acesso em: 21 set. 2020. 
Agora a cadeia pesou: aportes sobre os movimentos da Covid-19 no sistema prisional brasileiro Simone da Silva Ribeiro Gomes • Eduardo Pinheiro Urrutia

prisão domiciliar sem monitoramento eletrônico. O anterior se dá pela ausência do Albergue que funcionava anexo à penitenciária, destruído em um incêndio causado pelos próprios apenados em abril de 2018, que resultou na morte de cinco pessoas, dezenas de feridos e na interdição do local.

Há uma grande imersão dos agentes penitenciários neste contexto $^{13}$, ainda que em uma posição distinta às das pessoas presas, em uma relação configurada como de intenso convívio. E são estabelecidos graus de convivência, capazes de apreender e explicar, ao menos em parte, as angústias manifestadas pelos apenados e apenadas. A paraetnografia, portanto, permitiu uma investigação neste texto em que os sujeitos também fossem autores, em certa medida, das reflexões coletivas aqui propostas. Passado o incêndio do Albergue, por exemplo, notamos um aumento da proximidade dos pesquisadores com as pessoas presas, o que passou a incluir uma relativa participação deles na vida dos detentos egressos do sistema.

O trabalho dos agentes penitenciários não é extensamente abordado na Sociologia, mas alguns estudos (FERNANDES, 2002; BANDEIRA e BATISTA, 2009; MORAES, 2013) já retratam o intenso convívio desses trabalhadores com as pessoas presas. Assim, os papéis de buscar vagas de empregos nos convênios estabelecidos com a unidade, a realização de diligências nas residências, o acompanhamento de internações hospitalares, a gestão de redes de assistência social que oportunizam condições de subsistência para alguns e a busca de vagas de moradias para os desabrigados, e de internações daqueles viciados, dentre outros, são realizados por esses profissionais. Essas tarefas são realizadas de maneira conjunta com a rede pública municipal e com outras parcerias desenvolvidas, por exemplo, com as Pastorais Carcerárias, e com empresas privadas, configurando uma ampla imersão em diversos âmbitos da vida dos detentos. Muitos detentos procuram

\footnotetext{
13 Com a incidência do incêndio do albergue, aproximadamente 570 detentos foram transferidos para a prisão domiciliar. A gestão da população carcerária em prisão domiciliar ficou a cargo da administração do presídio. Desta forma, as relações entre os agentes penitenciários com as pessoas em cumprimento de pena foi intensificada para além das relações prévias intramuros. Pois, neste contexto, os agentes necessitam realizar com frequência diligências às residências dos apenados, a seus locais de trabalhos, efetuar acompanhamentos hospitalares, dentre outras. $O$ aumento dessa imersão dos agentes penitenciários foi significativo nesse período.
} 
Agora a cadeia pesou: aportes sobre os movimentos da Covid-19 no sistema prisional brasileiro Simone da Silva Ribeiro Gomes • Eduardo Pinheiro Urrutia

aproximar-se dos agentes por acreditarem que eles podem, em alguns momentos, Ihes oportunizar segurança, vagas de emprego, e até mesmo auxiliá-los em momentos de desespero ou recomeço.

Assim, muitas histórias de vidas das pessoas recolhidas nas instituições prisionais são acompanhadas proximamente pelos agentes penitenciários. Um convívio que vai além de compreender somente os motivos racionais de sua prisão e de gerenciar o cumprimento da pena. Nesse sentido, a abordagem etnográfica de Wacquant (2002a) aponta caminhos interessantes para a pesquisa proposta. Desde a entrada no sistema, o agente penitenciário acompanha mais do que o cumprimento penal dos detentos, mas os múltiplos sentimentos em torno dos seus recolhimentos. Os agentes escutam histórias sobre os sonhos, alegrias e perdas das pessoas presas e isso torna visível seu modo de compreender o mundo, e muitas vezes, de justificar sua posição nele.

Com a rápida expansão da pandemia de Covid-19 no sistema penitenciário, uma série de protocolos de cuidados foram publicados nos mais diversos órgãos. No arcabouço do Direito Penal brasileiro, eles tomaram forma legal por meio de portarias editadas pelas Varas de Execuções Criminais responsáveis por cada região. Em sua maioria, seguiram a Recomendação, $n^{\circ} 62$, do Conselho Nacional de Justiça, que direcionou as medidas a serem tomadas pelos tribunais e magistrados, no âmbito do sistema penal e socioeducativo, à prevenção e propagação de Covid-19 nos ambientes de encarceramento ${ }^{14}$. De acordo com o CNJ, ao menos 24 dos 27 estados cumpriram as orientações da portaria ${ }^{15}$.

Neste trabalho, em que pese algumas limitações ${ }^{16}$, analisamos alguns pontos que modificaram a rotina prisional, com novos impactos na problemática do encarceramento no Brasil. Primeiramente, apontamos para a decisão de redução de aglome-

\footnotetext{
14 CNJ - RECOMENDAÇÃO, n 62, DE 17 DE MARÇO DE 2020. Disponível em: https://www.cnj.jus.br/wp-content/uploads/2020/03/ 62-Recomenda\%C3\%A7\%C3\%A3o.pdf. Acesso em: 20 mar. 2020.

15 Agência CNJ de Notícias. Disponível em: https://www.cnj.jus.br/cnj-renova-recomendacao-n-62-por-mais-90-dias-e-divulga-novos-dados/. Acesso em: 13 jun. 2020.

16 Importa salientar que, embora o sistema de justiça e execução penal ocorra de forma similar nos estados, pois são pautados verticalmente por legislações nacionais, existem particularidades que o processo de análise de inspiração etnográfica deste trabalho não responderá, uma vez que a observação participante se deu no âmbito do sistema prisional do Estado do Rio Grande do Sul, especificamente na Penitenciária Estadual de Rio Grande.
} 
rações nas unidades judiciárias e prisionais, iniciativa que pode ser entendida na discussão contemporânea sobre alternativas para o desencarceramento. Esta questão afetou diretamente a interação pessoal na realização dos atos processuais. Afinal, tratamos da suspensão efetiva de parte das audiências em juízo e, consequentemente, da possibilidade de maiores atrasos processuais (GUIMARÃES e PARCHEN, 2020). De qualquer forma, seria difícil averiguar as consequências das demoras dessa natureza decorrentes da pandemia, dado o elevado número de pessoas encarceradas no Brasil. Ainda assim, algumas medidas foram tomadas pelos órgãos de justiça para minimizar o rápido alastramento da doença, como a execução de audiências por videoconferência e criação de portais de atendimento remoto. Paralelamente, foram observadas, nacionalmente, discussões para organizar projetos de lei que visassem suspender ou flexibilizar os prazos prescricionais durante a calamidade, um indício de preocupação institucional com o andamento processual.

Na pesquisa de campo com orientação etnográfica realizada, observamos um movimento de apreensão dentro do cárcere, e nesse sentido importa aferir que este primeiro ponto contribuiu para ampliar o sentimento de injustiça social que as pessoas presas exteriorizam. Segundo Skarperdas (2001), há uma série de lógicas reforçadas com maior facilidade no imaginário de um grupo encarcerado, devido às carências que experimentam em suas vidas, a hostilidade midiática da qual se veem vítimas e, igualmente, a representação enviesada das autoridades. Observamos relatos de anseios dos que aguardam decisões judiciais variadas: de progressão de regime - liberdade - indulto - remição etc; dos que esperam aflitos pelas audiências que poderiam decidir sua pena ou absolvição. Outro ponto contemplado, sobretudo nos detentos de pior situação financeira, é que a via que encontravam para solicitar seus direitos se dava majoritariamente por pedidos a seus familiares que se deslocavam aos Fóruns e Defensorias Públicas para encaminhar pedidos. Em relação ao último caso, ainda que recentemente tenham sido criados canais de acesso remoto, os 
Agora a cadeia pesou: aportes sobre os movimentos da Covid-19 no sistema prisional brasileiro Simone da Silva Ribeiro Gomes • Eduardo Pinheiro Urrutia

presos relatam que: primeiro, não conseguem contato com os familiares com o cancelamento das visitas; e segundo, como são pessoas de baixa renda e escolaridade, não saberão como fazer os pedidos de uma forma que não seja presencial.

O segundo movimento diz respeito a uma demanda do sistema prisional brasileiro, sua superlotação, questão reconhecida pelo Supremo Tribunal Federal (STF), dentro do "estado de coisas inconstitucional e violação a direito fundamental"17. Neste aspecto, a maioria das Varas de Execuções Criminais apoiaram as orientações do CNJ de março, que envolveram três pontos principais: a reavaliação das prisões provisórias, a concessão antecipada de progressão de regime e o benefício de prisão domiciliar ${ }^{18}$. Ambos os benefícios são condicionados a determinadas situações e prioridades, dentre elas: mulheres gestantes, lactantes, mães ou pessoas responsáveis por criança de até doze anos ou com deficiência; pessoas que se enquadrem no grupo de risco, tais como idosos, com doenças crônicas, imunossupressoras, respiratórias e outras comorbidades preexistentes que possam conduzir a um agravamento do estado geral de saúde a partir do contágio. Ademais, propõe especial atenção para pessoas com diabetes, tuberculose, doenças renais, HIV e coinfecções; que estejam em prisões preventivas e tenham excedido o prazo de noventa dias, e que os processos estejam relacionados a crimes praticados sem violência ou grave ameaça à pessoa; aos em cumprimento de pena em regime aberto, semiaberto e dívida alimentícia. Bem como, finalmente, a apenados com diagnóstico suspeito ou confirmado de Covid-19, mediante relatório da equipe de saúde, na ausência de espaço de isolamento adequado no estabelecimento penal.

De acordo com o Departamento Penitenciário Nacional $(D E P E N)^{19}$, órgão executivo vinculado ao Ministério da Justiça e Segurança Pública, responsável pelo controle e administração da

17 STF: Supremo Tribunal Federal. Brasília, 7 a 11 de setembro de 2015 - N: 798. Disponível em: http://www.stf.jus.br/arquivo/ informativo/documento/informativo798.htm. Acesso em: 8 mar. 2020.

18 Boletim de Notícias - CONJUR. Disponível em: https://www.conjur.com.br/2020-jun-12/cnj-renova-recomendacao-contaminacao-massa-presidios. Acesso em: 13 jun. 2020.

19 DEPEN - Departamento Penitenciário Nacional. Disponível em: https://www.gov.br/depen/pt-br/impacto-da-covid-19-no-brasil-em-relacao-a-outros-paises-1. Acesso em: 09 jul. 2020. 
Agora a cadeia pesou: aportes sobre os movimentos da Covid-19 no sistema prisional brasileiro Simone da Silva Ribeiro Gomes • Eduardo Pinheiro Urrutia

execução penal no país, 39.375 pessoas presas teriam sido colocadas em regime domiciliar desde o início da pandemia até o final de junho de 2020. O órgão também aponta que o Brasil ocupa a $16^{\circ}$ posição em um ranking mundial que analisa a taxa de infecção no cárcere, segundo um estudo que relaciona o número de presos contaminados com a população prisional. Ainda que essas liberações estejam condicionadas ao período de duração da pandemia, importa ressaltar a importância das decisões de desencarceramento em um país cuja taxa média é de $170 \%$ de ocupação prisional, ou seja, que evidencia a necessidade de um avanço considerável na discussão.

Finalmente, tratamos aqui de uma situação amplamente discutida na produção nas ciências sociais. Foucault $(2010)^{20}$ demonstra que os fins que levam ao encarceramento não foram observados, ao longo da história, como um fator de diminuição de violência, tal como Wacquant (2003, 2008, 2011, 2012, 2017) e Gilmore (2007) que problematizam singularidades que envolvem o sistema penitenciário, notadamente as discussões sobre a retração da proteção social e migração para um Estado mínimo. Assim, a expansão do aparato penal passa a ser um reflexo, não somente da ascensão da insegurança criminal, mas uma resposta institucional dos estados "a difusão da insegurança social moldada pela fragmentação do trabalho assalariado e pela reestruturação da hierarquia étnica" (BATISTA, 2012, p. 14). A busca de uma explicação para o aumento do encarceramento pela escalada do crime, portanto, não se reflete nas estatísticas oficiais, que demonstram que não houve um aumento dos crimes registrados, pelo contrário, eles se mantiveram constantes em números gerais. Em contrapartida às políticas de populismo penal (SOZZO, 2015) observadas, em que o discurso de um endurecimento das penas provaria a força repressora dos estados, é alarmante o aumento - e a ineficácia - da

\footnotetext{
20 Em Vigiar e Punir, Foucault (2010) aponta uma característica central das prisões, não associada à diminuição da violência, mas, sim, à demonstração de poder do Estado sobre os corpos. Essa se daria com a exposição a violências físicas e psicológicas na penalização sobre quem transgrida a lei. Um disciplinamento não apenas individual, mas coletivo. Para o autor, os fins empregados na elaboração dos ordenamentos jurídicos historicamente tem um conteúdo mais político do que prático. Um processo disciplinar que domestica os corpos a utilidades econômicas e a obediências políticas. Portanto, os "corpos dóceis" não se voltam contra ordens de seus superiores. A prisão se torna, nesse momento, um dos principais recursos de adestramento social e garantidora do poder estatal. Para o autor, o sistema prisional cumpre seu papel central, em suas funções ocultas, mas não, primordialmente, em diminuição dos índices de violência.
} 
Agora a cadeia pesou: aportes sobre os movimentos da Covid-19 no sistema prisional brasileiro Simone da Silva Ribeiro Gomes • Eduardo Pinheiro Urrutia

aplicação punitiva no último quarto de século XX e início do XX ${ }^{21}$ (GARLAND, 2006; 2008).

O supramencionado conjunto de medidas do Poder Judiciário, que liberou uma quantidade significativa de pessoas recolhidas, foi encarado como positivo por setores progressistas da população e pelos apenados. Entretanto, as determinações não foram suficientes, uma vez que não eliminaram a superlotação das unidades, e em certa medida, mitigaram os desafios de conter a contaminação de Covid-19 no sistema prisional, que, empiricamente, se mostram cada dia maiores. Dessa forma, foi frequente a observação de pessoas presas que externavam sentimentos de desânimo, como se não estivessem condenados apenas à reclusão, mas, neste momento, à morte. Como menciona Neiburg (2020), "nas prisões, a imobilidade já era uma condenação que o vírus agora multiplica." (NEIBURG, 2020, p. 2-3).

Um terceiro movimento é a caracterização das atividades próprias à execução penal, modificadas em decorrência da pandemia, em uma série de mudanças internas no cárcere brasileiro. Nesse aspecto, a portaria do CNJ frisa que tais pontos são de responsabilidade do Poder Executivo, dentre os quais sublinhamos: a realização de campanhas informativas; a aplicação de medidas preventivas de higiene; a criação de procedimentos de triagem nas unidades prisionais; a organização de protocolos de segurança quanto ao transporte compartilhado; o isolamento dos sintomáticos; o desenvolvimento de planos de cuidados e contingências à visitação e entrega de materiais; a restrição de saídas temporárias; a criação de medidas que compensem as restrições.

O que se observou, em um primeiro momento, foi um movimento geral dos órgãos públicos e servidores responsáveis pelas unidades prisionais em criar barreiras sanitárias para evitar a entrada e disseminação da Covid-19 nas prisões. Neste sentido, medidas de forte impacto na rotina prisional foram tomadas. Os primeiros reflexos foram observados no início da pandemia, com a

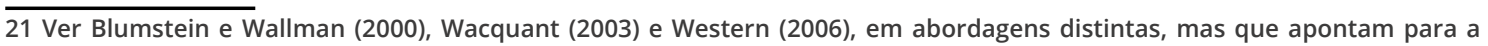
mesma conclusão. 
Agora a cadeia pesou: aportes sobre os movimentos da Covid-19 no sistema prisional brasileiro Simone da Silva Ribeiro Gomes • Eduardo Pinheiro Urrutia

fuga de aproximadamente 1400 presos em um único dia no estado de São Paulo, motivadas pela suspensão das saídas temporárias do regime semiaberto ${ }^{22}$. Este evento alertou a gestão prisional sobre a necessidade institucional de reforçar procedimentos de segurança e buscar um diálogo com a massa carcerária para justificar as razões das medidas. Ademais, tomaram impulso processos que compensassem as restrições, como a criação de salas de ligação telefônica e gestão de visitas por videoconferência, liberação de entrega de materiais, entre outros.

Entretanto, com 1456 unidades prisionais, é complicado precisar quais unidades no Brasil tiveram sucesso em suas medidas. A constatação principal é que os protestos, princípios de motins e rebeliões, tentativas de fuga, entre outros movimentos prisionais, se apresentaram como justificativas adicionais e interlocutores das ações das facções prisionais na pandemia. Reconhecemos aqui as facções, dentro do que Paiva (2019) conceitua como: coletivos que associam os indivíduos a um sistema material e simbólico, que embora possuam alcance e contextos socioculturais variados, têm pelas manifestações daqueles que ocupam as posições hierárquicas elevadas, os direcionamentos que sustentam e orientam seus agenciados, dentro e fora das prisões.

A sensação de injustiça sofrida por uma grande maioria de pessoas presas, que enfrenta maiores atrasos em seus processos e restrição de visitas e materiais, começou a ganhar uma grande proporção à medida que os procedimentos tomados demonstravam suas falhas e a Covid-19 adentrava e se expandia nos estabelecimentos prisionais. Furor que pode ser observado através de uma nota "Salve Geral", publicada pelo Primeiro Comando da Capital (PCC) ${ }^{23}$, em que os membros apontavam mortes e contaminações em um dos pavilhões na unidade Venceslau 2, em São Paulo, e afirmavam não estarem pedindo regalias, mas sim, humanidade. A deflagração de uma guerra fica

22 Disponível em: https://www.otempo.com.br/brasil/presidios-registram-fuga-em-massa-de-1-356-presos-em-sao-paulo-1.2311852. Acesso em: 17 mar. 2020.

23 Disponível em: ttps://br.noticias.yahoo.com/em-bilhete-pcc-denuncia-que-presos-com-covid-19-estariam-sendo-misturados-aos-saudaveis-194057833.html. Acesso em: 17 jun. 2020. 
Agora a cadeia pesou: aportes sobre os movimentos da Covid-19 no sistema prisional brasileiro Simone da Silva Ribeiro Gomes • Eduardo Pinheiro Urrutia

subentendida no comunicado, caso porventura for colocado esse vírus de propósito para matar nossos irmãos e a população carcerária no geral, além da constatação de que há uma quebra do contato com os familiares, e que não houve uma rápida separação dos grupos de risco, no começo da pandemia.

Além disso, com o avanço da Covid-19 no sistema prisional, foram intensificadas as críticas aos procedimentos ou condutas incoerentes de agentes institucionais quanto aos protocolos de prevenção ao vírus. No Espírito Santo, uma ação civil determinou ${ }^{24}$ que os servidores das unidades prisionais [...] "ao estarem de máscaras, tenham sua identificação, com nome e matrícula exposta no uniforme para permitir seu reconhecimento e controle em caso de denúncias". Com efeito, esta decisão envolve mais do que salvaguardar os apenados para casos de violência e tortura, mas também uma forma de pressionar o Poder Executivo a cumprir as medidas preventivas, antecipando a possibilidade de punições para casos de negligência. Cenário esse que demonstra o reconhecimento de problemas institucionais de contenção, bem como aponta para uma responsabilização pessoal de servidores na disseminação do vírus no contexto.

\section{Os movimentos das pessoas presas: fuga, ausência de visitas e apreensão generalizada}

Os primeiros movimentos observados nas unidades brasileiras, ainda em março, foram de fuga, seguido do anúncio de suspensão de visitas. Em Mongaguá, São Paulo, mas também em outros presídios do estado, foram observadas fugas possivelmente decorrentes dessa situação. Em todo o país, a movimentação das pessoas presas, ora de ameaça, com a possibilidade de rebeliões e fuga em massa, ora com o uso de repertórios de ação coletiva,

24 Sob o número de processo 0008963-28.2020.8.08.0024 e apreciada pela 4ª Vara da Fazenda Pública, onde a decisão do Juízo de Direito obrigou a Secretaria de Justiça do Estado. 
Agora a cadeia pesou: aportes sobre os movimentos da Covid-19 no sistema prisional brasileiro Simone da Silva Ribeiro Gomes • Eduardo Pinheiro Urrutia

como protestos de visitas organizados ${ }^{25}$, são emblemáticos desse primeiro momento.

Ao mesmo tempo, no trabalho de inspiração etnográfica, observamos nas falas das pessoas presas como seu afastamento forçado é repleto de idiossincrasias, dado que o ambiente prisional, além de superlotado, é também confinado. Afinal, tratamos de pessoas que vivem a maior parte do dia aglomeradas em celas pequenas, em espaços tão exíguos e superlotados que muitas vezes há a necessidade de revezamento para o descanso. Nesses, é frequente a divisão de camas, conhecidas internamente por jegas, com sarcófagos embaixo, posicionados abaixo de outros dormitórios, bem como de jégas de morcego, redes localizadas acima das camas ou pregadas nos cantos das paredes. ${ }^{26}$.

Um dos movimentos notados no cárcere após a irrupção da pandemia foi o aumento da ansiedade no ambiente prisional, o que se deu pela dificuldade dos detentos de receberem notícias de seus familiares e a preocupação subsequente que aparece com os vínculos próximos, como algo que desperta tanta aflição quanto a possibilidade de contrair a doença. Segundo a fala de um homem preso: "Meu medo é minha mãe, meu pai eu nem sei, pai eu na real nem tenho, nunca tive, mas minha mãe, meu medo é acontecer algo com ela, porque já é velhinha e doente, eu aqui, sem saber, sem ter como fazer nada"27. De forma que a única referência familiar que ele aparenta ter pertence a um grupo de risco, e ele não tem nenhuma notícia. A dificuldade de contato e notícias foi comum a muitas pessoas durante a pandemia, o que ocasionou um aumento das chamadas de vídeos e lives nos mais diversos contextos e formatos. Porém, neste caso, os meios de comunicação informacional não aparecem como uma opção, ao menos para parte significativa dos apenados.

25 Um exemplo pode ser visto em: https://www.metropoles.com/distrito-federal/covid-19-parentes-de-detentos-pedem-retorno-de-visitas-em-presidios-do-df. Acesso em: 12 set. 2020.

26 Salientamos que estes são nomes aferidos pelos apenados nos presídios observados, e que estas nomenclaturas mudam em diferentes regiões do país. Mas as adaptações internas que aumentam o número de locais de descanso ocorrem de forma similar na maioria das unidades prisionais do Brasil.

27 Homem preso, 33 anos, julho de 2020. 
Agora a cadeia pesou: aportes sobre os movimentos da Covid-19 no sistema prisional brasileiro Simone da Silva Ribeiro Gomes • Eduardo Pinheiro Urrutia

Nesse momento, o aumento dos telefonemas previstos na decisão do CNJ de março apareceu como uma compensação para os apenados ${ }^{28}$. Há quem consiga saber notícias de seus familiares, seja pelas ligações regularizadas e videochamadas que algumas unidades disponibilizaram ou por meio dos celulares que adentram o sistema prisional na forma de rebolo, um arremesso ilegal. Importa apontar que o distanciamento social está posto para eles a partir de seus vínculos mais próximos, com a falta de acesso das visitas de suas esposas e filhos: "O mais difícil tem sido as visitas né, aguentar isso aqui sem ver e mal saber dos meus filhos, é complicado"29.

Com exceção de alguns profissionais da linha de frente, que devido ao alto risco de exposição à doença optaram por se afastar de suas ligações familiares mais próximas, para os apenados esta questão se apresentou como a norma. A decisão do CNJ de março institucionalizou a ligação em salas de conferências, ainda que acompanhada por assistentes sociais, quando anteriormente essa só se dava de forma clandestina, com a entrada por rebolo nas unidades. $\mathrm{O}$ acompanhamento de notícias de familiares doentes e a despedida dos familiares, para algumas parcelas da população, também foi limitado. Para os presos acrescenta-se a impossibilidade de dividir os sentimentos, lutos etc. Em outra fala, um homem preso complementa que: "Pesa é a solidão, a gente fala uns com os outros, mas não é a mesma coisa" ${ }^{\prime 30}$. Nota-se que a pandemia acrescenta adversidades que ampliam os sofrimentos dentro das unidades prisionais.

São distintos medos os que figuraram no decorrer da observação etnográfica. Um detento aponta: "Meu medo é pegar esse troço, ter que ir para essas celas isoladas, perder a cama que tenho aqui no canto, e lá, não abrem para nada, nem dão notícias da família na rua"31. Observamos assim os medos de perder espaços adquiridos em sua estadia nas unidades, de irem para celas que

28 Segundo a reportagem O PCC e os vírus das rebeliões. Disponível em: https://piaui.folha.uol.com.br/o-pcc-e-o-virus-das-rebelioes/. Acesso em: 8 ago. 2020.

29 Homem preso, 42 anos, julho de 2020.

30 Homem preso, 29 anos, julho de 2020.

31 Homem preso, 24 anos, julho de 2020. 
Agora a cadeia pesou: aportes sobre os movimentos da Covid-19 no sistema prisional brasileiro Simone da Silva Ribeiro Gomes • Eduardo Pinheiro Urrutia

são completamente isoladas, como celas de seguro, que se assemelham às antigas "solitárias". Outrora utilizadas como forma de castigos, agora são usados como espaços para isolar muitos que contraem a doença. Além da perda de espaços, aparece também a questão das privações materiais, "Antes a visita vinha, sabia o que a gente precisava e na outra semana tava aí, e agora ficamos a nada, e é o que tem"32. O que implica a perda de objetos individuais de higiene básica, alimentação, suprimentos, aos quais tinham acesso pelas visitas. E constituem pontos que ampliam suas misérias e, consequentemente, tornam-se fatores que agregam vulnerabilidades frente à presença do vírus.

Em alguns casos, as mudanças decorrentes da pandemia, como o cancelamento de audiências, os atrasos processuais, a limitação de acesso a visitas e informações, entre outras, impõemse de maneira conjunta na vida de pessoas aprisionadas, como aparece na fala a seguir:

Eu nem sei bem porque tô preso, sei que é porque briguei com minha mulher, eu sei que errei, mas não consegui falar com ninguém, me desculpar, sei que a minha irmã tá lutando por mim, porque o guarda falou que ela veio aí na frente, mas desde de que entrei, a um mês e meio, não sei de nada. Como todos tão, quando alguém virá me ouvir, se vou sair, nada! Só medo e tristeza, [choro...]. ${ }^{33}$

Ademais, dentro das rotinas prisionais, as visitas assumem significados distintos, sobretudo quando levadas em consideração as perspectivas dos apenados. É possível identificar nos dias que antecedem as visitações um trabalho de limpeza e preparo de refeições por parte das pessoas presas, em um movimento de organização dos espaços para recepção das visitas. Além do que, identificam códigos de regras que se estabelecem entre os detentos para os dias de visitação, seja pela proibição de olhar e cumprimentar as visitas de outros apenados, seja pela moderação

32 Homem preso, 30 anos, julho de 2020. 33 Homem preso, 21 anos, julho de 2020. 
Agora a cadeia pesou: aportes sobre os movimentos da Covid-19 no sistema prisional brasileiro Simone da Silva Ribeiro Gomes • Eduardo Pinheiro Urrutia

de confrontos internos ou com os guardas nesses dias, já identificado por Barbosa (2019).

Com a impossibilidade das visitas, novos significados puderam ser observados. Na fala de um apenado, identificamos alguns pontos: "Sem visita, pesou a cadeia. Parece que os dias passavam mais rápido, nós nos envolvíamos na limpeza, arrumando tudo, esperando o próximo dia que eles vinham. Agora o tempo não passa, é um inferno, nem tem porque arrumar nada"34. A apreensão que o homem apresenta não diz respeito exclusivamente ao rearranjo das rotinas internas, mas conjuntamente, a uma mudança de percepção sobre o passar do tempo no cárcere. Falta de motivação, desânimos, inquietudes, tentativas de suicídio, solicitação de acompanhamento psicológico e médico também foram ampliados nesse momento. Embora não existam indicadores precisos sobre essas situações, são questões que são ressaltadas quando nos detemos sobre as condições do cárcere no momento da pandemia. A fala de uma mulher presa é explícita a respeito da desesperança frente à situação em que vivem:

O sentimento é de desespero por não ter contato da família, não tem uma alegria, eu juro que estou entrando em depressão, antes a gente via a fila com as famílias chegando né, tinha a alegria das crianças, dos familiares de todo mundo, agora não tem um motivo para viver aqui35.

Outra situação drástica é emblemática das nuances do desencarceramento e da incipiente discussão da abolição prisional no Sul Global, em especial em contextos de miséria absoluta. Na cidade de Rio Grande, no mês de agosto, um homem preso recebeu o benefício de prisão domiciliar mediante o uso de tornozeleira eletrônica, mas por viver em situação de extrema pobreza e não possuir residência fixa, não poderia ser colocado em situação de prisão domiciliar até que tivesse um local para cumprir as condições impostas. Ademais, seu caso foi agravado por ter testado positivo

34 Homem preso, 34 anos, julho de 2020. 35 Mulher presa, 44 anos, agosto de 2020. 
Agora a cadeia pesou: aportes sobre os movimentos da Covid-19 no sistema prisional brasileiro Simone da Silva Ribeiro Gomes • Eduardo Pinheiro Urrutia

para Covid-19 um dia antes de receber a concessão judicial. Em situações semelhantes antes da pandemia, as assistentes sociais da penitenciária procurariam vagas junto aos estabelecimentos que acolhem moradores de rua para abrigar essas pessoas. Porém, neste caso isso não se mostrava uma alternativa, uma vez que não havia como encaminhar uma pessoa que testara positivo. Desta forma, mesmo possuindo o benefício de prisão domiciliar, foi necessário esperar o período de quarentena recolhido na penitenciária, e somente após novo laudo médico, comprovando que não estava mais em período de contágio, o homem foi liberado para cumprir prisão domiciliar em um alojamento disponibilizado pela Pastoral Carcerária. A demora do movimento aqui observada diz respeito ao acréscimo de dias de detenção involuntário que o vírus - e a pobreza extrema - impuseram a uma pessoa, cenário frequente em contextos de discursos bem-sucedidos do populismo penal, mas que na realidade carcerária se mostra mais complexa.

\section{Considerações Finais}

\section{3}

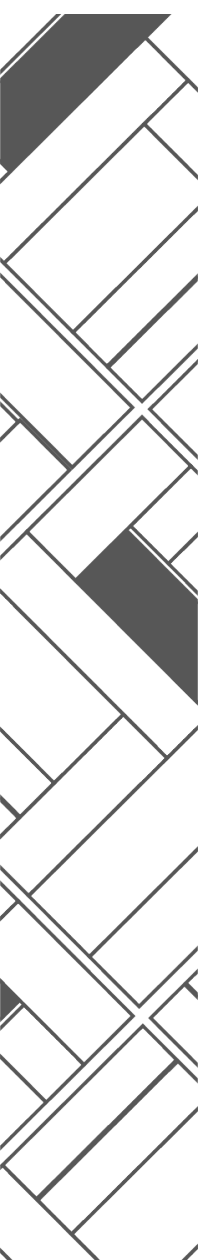

Ao examinar alguns dos significados sociais da prisão, especialmente quando são tensionadas perspectivas que partem do sujeito aprisionado, observamos discussões situadas em polos opostos no imaginário coletivo. A dualidade perversa a que fizemos menção diz respeito, de um lado, aos que entendem a prisão atual como um sistema desumanizado, e que almejam alternativas penais adequadas para a ressocialização. De outro, aqueles que desejam que estas funcionem como masmorras, pois acreditam que os apenados merecem ser expostos a todos os tipos de mazelas ${ }^{36}$. Desta forma, opiniões se dividem entre a favor ou contra as possibilidades de desencarceramento. Tal divergência é observada também entre os poderes da república, pois ao passo que o Poder Judiciário - via CNJ - projetava medidas

36 Relatos de denúncias publicados pela Pastoral Carcerária apontam negligências intencionais de prestação assistencial à saúde no ambiente prisional durante a pandemia. Disponível em: https://carceraria.org.br/combate-e-prevencao-a-tortura/ pastoral-carceraria-divulga-relatos-e-denuncias-sobre-o-sistema-carcerario-em-tempos-de-pandemia. Acesso em: 27 abr. 2020. 
Agora a cadeia pesou: aportes sobre os movimentos da Covid-19 no sistema prisional brasileiro Simone da Silva Ribeiro Gomes • Eduardo Pinheiro Urrutia

de liberação de apenados no início da pandemia no Brasil, o Poder Executivo, na figura do então Ministro da Justiça Sérgio Moro, se manifestava contrário às decisões. Em sua conta na rede social Twitter, ele declarava: "O coronavírus não pode ser usado como subterfúgio para soltar qualquer criminoso. Criminosos perigosos ou responsáveis por crimes graves, de qualquer natureza, devem ser mantidos presos. Aliás, não há nenhum caso confirmado de preso com coronavírus no Brasil" ${ }^{37}$.

Essas demonstrações, emblemáticas de dicotomias utilizadas nos debates, como afirma Zelizer (2009), estão presentes em relações sociais que resultam de múltiplas combinações. E neste caso, dada à temática da violência e prisão, há uma extensa problemática, que coloca em questão inclusive processos de justiça, legalidade, sociedade e humanidade. Assim, ultrapassa a dualidade de um discurso de merecer ou não ser condenado ao vírus, logo, deve ser analisada também no bojo da individualização das penas e dos sentidos mais amplos da prisão.

A decisão de março do CNJ, como observada no trabalho de campo, expôs dinâmicas internas do sistema prisional e uma série de movimentos das pessoas presas, similares à realidade no resto do país. O texto buscou explorar algumas das nuances refletidas no sistema penitenciário, que, na busca por achatar a curva, demonstrou uma preocupação com a manutenção da ordem carcerária, em uma gestão da crise que inovou, como o uso de tecnologias de videochamadas para mitigar os efeitos do isolamento adicional das pessoas presas (GODOI; CAMPELLO e MALLART, 2020). O trabalho parte de convergências nos estudos prisionais nas quais há uma "visão de que o crime é um fenômeno a ser entendido e explicado ou um problema a ser resolvido. Embora na prática exista um cruzamento entre eles, as duas abordagens são fundamentalmente diferentes" (DEWEY, 2016, p. 9). Para tanto, refletir sobre o sistema prisional a partir da dinâmica dos relacionamentos das pessoas presas possibilita a observação de como se organizam as relações sociais em espaços

37 Disponível em: https://www.correiodopovo.com.br/not\%C3\%ADcias/pol\%C3\%ADtica/coronav\%C3\%ADrus-n\%C3\%A3o-pode-ser-usado-para-soltar-criminoso-diz-moro-1.409371. Acesso em: 7 ago. 2020. 
Agora a cadeia pesou: aportes sobre os movimentos da Covid-19 no sistema prisional brasileiro Simone da Silva Ribeiro Gomes • Eduardo Pinheiro Urrutia

de confinamento e as decorrências de doenças epidêmicas nestes locais.

\section{Referências}

ALVES, Tamires M; GUSIS, Gabriela Laura. Entrevista com Eugenio Raúl Zaffaroni. Revista Estudos Políticos, v. 8, n. 16, p. 4-10, 2019.

BANDEIRA, Lourdes; BATISTA, Analia Soria. Trajetórias Profissionais e carreira dos agentes penitenciários: Distrito Federal e Goiás. In: SANTOS, José Vicente Tavares (Org). Subsídios para construção de um novo fazer segurança pública. Brasília: SENASP, 2009.

BARBOSA, Antonio. Política e moral nas prisões brasileiras.

Tempo Social, v. 31, n. 3, p. 121-140, 2019.

BATISTA, Vera Malaguti. História sem fim. Curso livre de abolicionismo penal. Rio de Janeiro:[sn], 2004.

BATISTA, Vera Malaguti (org.). Loïc Wacquant e a questão penal no capitalismo neoliberal. 2. ed. Rio de Janeiro: Revan, 2012. BLUMSTEIN, Alfred; WALLMAN, Joel (Org). The Crime Drop in America. Nova York: Oxford University Press, 2000.

BONATO, Patricia; VENTURA, Carla. A; CAETANO, Maria Helena. Covid-19 e o Sistema de Justiça Criminal Brasileiro: da Crise Sanitária à Violação Epidêmica do Direito Humano à Saúde no Contexto Prisional. RDP, Brasília, v. 17, n. 94, 493-521, jul./ago. 2020.

CAMPELLO, Ricardo Urquizas. Vírus e vermes: Covid-19, política penitenciária e a reatualização do leprosário. Horizontes ao Sul, 2020. Disponível em: https://www.horizontesaosul.com/ single-post/2020/03/27/VIRUS-E-VERMES-COVID-19-POLITICAPENITENCIARIA-E-A-REATUALIZACAO-DO-LEPROSARIO. AcesSO em: 12 set. 2020. 
Agora a cadeia pesou: aportes sobre os movimentos da Covid-19 no sistema prisional brasileiro Simone da Silva Ribeiro Gomes • Eduardo Pinheiro Urrutia

CONSELHO NACIONAL DE JUSTIÇA. Registro de Contágios/ Óbitos, 2020. Disponível em: https://www.cnj.jus.br/sistema-carcerario/covid-19/registros-de-contagios-obitos/ Acesso em: 22 set. 2020.

DAVIS, Angela. Estarão as prisões obsoletas? Rio de Janeiro: Difel, 2019.

DAVIS, Brandon. Feeling Politics: Carceral Contact, Well-Being, and Participation, 2020. Policy Studies Journal. doi:10.1111/ psj.12408

DEWEY, Matías. Porous Borders: The Study of Illegal Markets from a Sociological Perspective. Max Planck Institute for the Study of Societies: Cologne, 2016.

FERNANDES, Rita de Cássia Pereira et al. Trabalho e cárcere: um estudo com agentes penitenciários da Região Metropolitana de Salvador, Brasil. Cadernos de Saúde Pública, v. 18, n. 3, p. 807816, 2002.

FOUCAULT, Michel. Vigiar e Punir. 38 ed. Petrópolis, RJ: Vozes, 2010.

GARLAND, David. Castigo y Sociedad Moderna: Un estudio de teoría social. México D.F.: Siglo XXI Editores, 2006.

GARLAND, David. A Cultura do Controle: Crime e ordem social na sociedade contemporânea. Rio de Janeiro: Revan, 2008.

GILMORE, Ruth. Golden Gulag: Prisons, Surplus, Crisis, and Opposition in Globalizing California. London: University of California Press, 2007.

GUIMARÃES, Rodrigo R.; PARCHEN, Andrelize G. Videoconferência na Inquirição de Testemunhas em Tempos de Covid-19: Prós e Contras na Percepção dos Atores Processuais Penais. RDP, Brasília, v. 17, n. 94, 493-521, jul./ago. 2020.

GODOI, Rafael; CAMPELLO, Ricardo e MALLART, Fabio. O colapso é o ponto de partida: Entrevista com o Mecanismo Estadual de 
Agora a cadeia pesou: aportes sobre os movimentos da Covid-19 no sistema prisional brasileiro Simone da Silva Ribeiro Gomes • Eduardo Pinheiro Urrutia

Prevenção e Combate à Tortura do Rio de Janeiro sobre prisões e a Covid-19. Dilemas - Reflexões na Pandemia, 2020. Disponível em: https://www.reflexpandemia.org/texto-21. Acesso em: 1 fev. 2021.

HELEPOLOLEl, Justin. Case Study: COVID-19, Care, and Incarceration in Massachusetts. Rethinking Marxism: a journal of Economics, Culture and Society., 2020. Disponível em: http://rethinkingmarxism. org/Dossier2020/index.html. Acesso em: 1 fev. 2021.

ISLAM, Gazi. Practitioners as theorists: Para-ethnography and the collaborative study of contemporary organizations.

Organizational Research Methods. v. 18, n. 2, p. 231-251, 2015.

LOURENÇO, Luiz Claudio; ALMEIDA, Odilza Lines de. “Quem mantém a ordem, quem cria desordem": gangues prisionais na Bahia. Tempo social, v. 25, n. 1, p. 37-59, 2013.

MACHADO, Jean Carlos, BOLDORI, Jilia Diane Martins, DALMOLIN, Marcelo Dalton, et al. A incidência de tuberculose nos presídios brasileiros: revisão sistemática. Revista de Atenção à Saúde. v.

\section{7} 14, no 47, p. 84-88, 2016.

MAIA, Clarissa Nunes et al. (Orgs.). História das prisões no Brasil. v.1, Rio de Janeiro: Rocco, 2009.

MORAES, Pedro Bodê. A identidade e o papel dos agentes penitenciários. Tempo Social, v. 25, p. 131-147, 2013.

NEIBURG, Frederico. Vidas, Economia e Emergência. Anpocs Boletim Especial n. 22 - 16/04/2020. Disponível em: http://www. anpocs.com/index.php/ciencias-sociais/destaques/2335-boletim-n-22-vidas-economia-e-emergencia?fbclid=IwAR3fgVKFeoacFPNa5mdEJ6varxP20p6nnDSvsUd8mBVMKBo8GHxFyZECIIg. Acesso em: 8 ago. 2020.

PAIVA, Luiz Fábio. "Aqui não tem gangue, tem facção": as transformações sociais do crime em Fortaleza, Brasil. Cadernos CRH, Salvador, v. 32, n. 85, p. 165-184, 2019. 
PASTORAL CARCERÁRIA. Relatos e Denúncias sobre o sistema carcerário em tempos de pandemia. São Paulo. CNBB. Disponível em: https://carceraria.org.br/combate-e-prevencao-a-tortura/pastoral-carceraria-divulga-relatos-e-denuncias-sobre-o-sistema-carcerario-em-tempos-de-pandemia. Acesso em: 27 abr. 2020.

PASSETTI, Edson; BATISTA, Roberto Dias B. Conversações abolicionistas uma critica do sistema penal e da sociedade punitiva. Instituto Brasileiro de Ciências Criminais, São Paulo, 1997.

PASSETTI, Edson. Abolicionismo penal, medida de redução de danos e uma nota trágica. verve. n. 7, 2005.

PEIRCE, Jennifer. "Overuse of Pretrial Detention in tension with Judicial and Prison Reforms in the Dominican Republic". Latin American Law Review, n. 5: 45-69, 2020.

SALLA, Fernando et al. As rebeliões nas prisões: novos significados a partir da experiência brasileira. Sociologias, v. 8, n. 16, 2006.

\section{8}

SKARBEK, David. Governance and Prison Gangs. The American Political Science Review: v. 105, n. 4, 2011.

SKARBEK, David. The social order of the underworld: How prison gangs govern the American penal system. Oxford University Press, 2014.

SOZZO, Maximo. Populismo penal en Argentina: una historia en tres episodios. Buenos Aires: Mimeo, 2015.

VALENÇA, Manuela; FREITAS, Felipe. O Direito à Vida e o Ideal de Defesa Social em Decisões do STJ no Contexto da Pandemia da Covid-19. RDP, Brasília, v. 17, n. 94, 493-521, jul./ago. 2020.

WACQUANT, Loïc. Corpo e Alma. Notas Etnográficas de um Aprendiz de Boxe. Rio de Janeiro: Relume Dumará, 2002a.

WACQUANT, Loïc. The Curious Eclipse of Prison Ethnography in the Age of Mass Incarceration. Ethnography, 3(4), 371-397. 2002b 
Agora a cadeia pesou: aportes sobre os movimentos da Covid-19 no sistema prisional brasileiro Simone da Silva Ribeiro Gomes • Eduardo Pinheiro Urrutia

WACQUANT, Loïc. Punir os pobres: a nova gestão da miséria nos Estados Unidos. Rio de Janeiro: Revan, 2003.

WACQUANT, Loïc. As duas faces do gueto. São Paulo: Boitempo, 2008.

WACQUANT, Loïc. As Prisões da Miséria. 2.ed. ampl. Rio de Janeiro: Zahar, 2011.

WACQUANT, Loïc. Os condenados da cidade: estudos sobre marginalidade avançada. 2. ed. Rio de Janeiro: Revan, 2017.

WESTERN, Bruce. Punishment and Inequality in America. Nova York Russell Sage Foundation, 2006.

ZELIZER, Viviana. Dualidades perigosas. Mana, v. 15, n. 1, p. 237256, 2009. 